\title{
Longitudinal comparison of Finnish and US online shopping behaviour among university students: The five-stage buying decision process
}

Received (in revised form): 10th August, 2006

\section{Charles Comegys}

is the Ciejek Chair of Business and is Associate Professor of Marketing in the Girard School of Business \& International Commerce at Merrimack College, USA. Dr Comegys' research interests include research methodologies and internet purchase behaviour. His articles appear in numerous publications including the Journal of Marketing Theory and Practice, Practical Assessment, Research \& Evaluation, Journal of Internet Commerce, Journal of Business Education, Journal of Small Business Management, Journal of the Academy of Business Education, Management Research, Atlanta Economic Review, Operations Management Review, and Marketing News. He has served on the Board of Directors of the American Marketing Association, the Marketing Research Association, and currently is on the Board of the Marketing Educators' Association.

\section{Mika Hannula}

holds MSc (Eng) and DrTech in Industrial Management and Engineering. Professor Hannula is currently the Head of the Institute of Business Information Management and the Director of the Degree Program of Information and Knowledge Management at Tampere University of Technology, Finland.

\section{Jaani Väisänen}

received his Master's Degree in Statistics from the University of Tampere, Finland. He currently works as a researcher in the Institute of Business Information Management at Tampere University of Technology, where he is also completing his doctoral studies. His current research interests are related to electronic commerce and especially in the use of search engines in the marketing field.

Charles Comegys, PhD Girard School of Business \& International Commerce Merrimack College 315 Turnpike Street North Andover, MA, USA Tel: +1 (978) 8375409 Fax: +1 (978) 8375086 Email: ccomegys@merrimack.edu

\section{INTRODUCTION}

The use of the internet has rapidly grown from its early years, thanks to the so-called 'Net Generation'. The Net Generation is said to consist of young people and adolescents born between 1977 and 1997. ${ }^{1}$ These people have been using the latest information technology devices almost throughout their entire lives, which makes them highly literate in online activities. This paper is focused on the online shopping behaviour of a key segment of two of the world's most advanced IT nations: Finnish and US university students. ${ }^{2}$ Although there has been ample discussion and criticism 
concerning the use of university students as test subjects, they fit well for this study as university students in the target countries are typically extensive users of the internet. This study is not intended to gather information pertaining to the proportion of the population that use the internet, but to understand the buyer decision process of those that do. Thus, university students, although not a truly representative sample, do reflect the behaviour of heavy online users.

Information about this segment has been gathered at two points in time: in 2002 and 2004 in Finland, and in 2002 and 2005 in the USA. The focal point of this study is to compare the differences and relations between the two samples, and the two nations. Among different models of consumer behaviour, perhaps the most well known is the five-stage model, ${ }^{3}$ which describes the consumer purchase event as a process which starts long before the actual purchase is consummated and continues after the purchase. This model is the backbone of the present research, which depicts the changes in the process and the factors that underlie them between the samples. The results give marketers an insight into how the Finnish and US online marketplace has changed in the past two years in the customer's eyes, along with some implications of where it might be in another two years.

Electronic commerce offers many advantages over traditional commerce that are useful to both marketers and customers. For example, customer relationship management (CRM) helps the company to gather information and maintain relations to the customer, who in turn will get precisely the information they need. ${ }^{4}$ This flexibility is said to be one of the internet's greatest values for marketers when compared with conventional methods of commerce. ${ }^{5}$ On the other hand, there are still opinions that even with all these new innovations and abilities, the internet has not changed the basic buying patterns of consumers. ${ }^{6}$

These mixed opinions are to the benefit of the present study, which aims to combine the aspects of flexibility with fixed purchasing patterns. Thus, the study assumes that buying behaviour follows the five-stage model with some modifications for the online situation, and considers the changes that have occurred in two years within the framework of the model. Assuming that the model is a 'closed space,' which completely covers every aspect of purchase, it is possible to draw conclusions on which parts of the model are more relevant to customers than others.

\section{BACKGROUND}

The five-stage buying decision process model is a widely used tool for marketers to gain a better understanding about their customers and their behaviour. $^{7}$ The idea of the model is that when a customer purchases an item, the purchase event is a forward-moving process, which begins long before the actual purchase and continues even after the purchase is made. As the name implies, there are five different stages in the process, which are need recognition, information search, evaluation of alternatives, purchase decision, and postpurchase behaviour (see Figure 1). Following is a review of each of these stages in the consumer buying process.

\section{Need recognition}

The buying process begins with need recognition (sometimes referred to as problem recognition), where the buyer senses a difference between their actual state and a state they desire. This need can be triggered by either an internal 


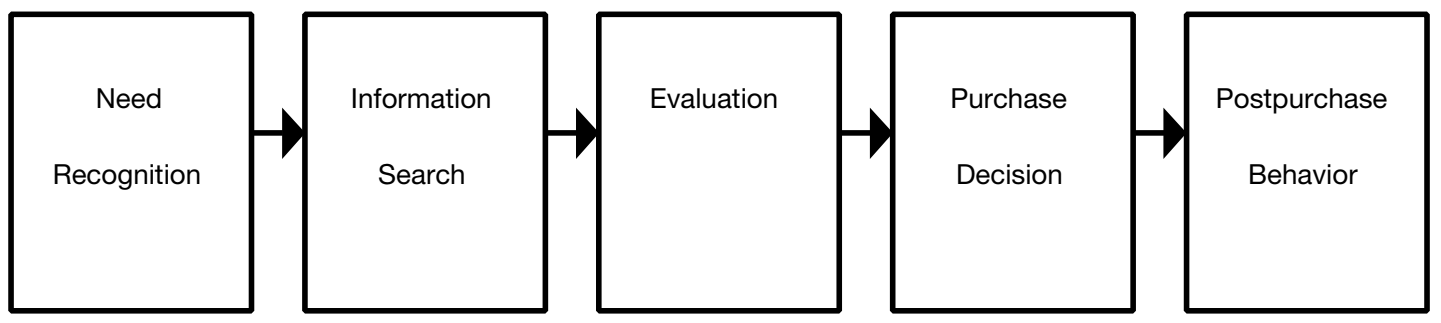

Figure 1: Five stage buying decision process model

(hunger, thirst) or external (passing through McDonald's stimulates hunger) stimuli. $^{8}$

Other factors besides differences in the buyer's actual and desired state influence need recognition as well. One of the directly observable influences is demographic factors, including age, sex, income, race, education, household size, and marital status. ${ }^{9}$ There are also inferred influences which affect need recognition. Psychological factors play a major role in these inferred influences.

Of these psychological factors, motivation is the basis of all consumer behaviour. ${ }^{10}$ Although there is no general agreement among psychologists on the best way to classify consumer needs as far as motivation goes, Kinnear and Bernhardt ${ }^{11}$ divide the motivational needs into physiological and psychological needs. The former include, for example, the need for food and shelter, while the latter are generated by one's social environment.

Perception reflects how the customers see themselves and their surroundings, which in turn affects not only the need recognition phase, but the other phases as well. ${ }^{12}$ Depending on the consumer's needs and perceptions, need recognition may take different forms. In addition to purchasing something totally new or replacing a broken/outdated item, consumers may replace a product that fills their needs completely with another. This phenomenon is called variety seeking. ${ }^{13}$ Van Trijp, Hoyer and Inman ${ }^{14}$ have suggested that higher purchase frequencies stimulate repeat purchasing rather than variety-seeking behaviour, which gives e-marketers a good reason to make the threshold for shopping as low as possible.

\section{Information search}

The next stage in the buying process is information search, where the consumer uses different channels to gather information about available products, which might fulfil the needs discussed above. Kotler ${ }^{15}$ defines two levels of arousal during the information search phase. In the milder state, heightened attention, the consumer just becomes more familiar with the different products that might be suitable for them. In this state, the consumer only pays attention to advertisements and conversations about the subject. In the next state, active information search, the consumer actively engages these conversations and searches for information about different brands, models, etc.

Kotler $^{16}$ also defines four methods by which consumers receive product/service information. Personal sources include family and friends. Commercial sources include advertising and salespersons. Public sources include mass media and consumer-rating organisations.

Experimental sources include examining and using the product itself. Most of the information comes from the commercial sources, but according to Dubois, ${ }^{17}$ the 
most effective information comes from personal sources.

There are also differences in information search with different levels of expertise. Alba and Hutchinson ${ }^{18}$ report that experts are able to search more efficiently and therefore have more knowledge of available products. They point out a common case, however, where experts do less actual searching because they have already gathered previous information about the products in their memory (internal search). When Beatty and Smith ${ }^{19}$ propose that product class knowledge is negatively associated with the search effort, it can be concluded that often those with intermediate knowledge of the desired product do most of the searching, although its efficiency might not rival the experts'. Considering the online environment, expertise about the product and expertise about the search process must be separated. As previously stated, those with excellent knowledge about the product might reduce the amount of information search, and better knowledge about the online search methods can actually do the same, as the search procedure becomes more effective. In addition, better knowledge about the desired product can improve the quality of the consideration set (discussed later in this paper), thus also reducing the search time and improving the search efficiency. ${ }^{20}$

Another factor affecting of the amount and type of information search is the perceived risk (uncertainty) involved with the purchase. In their study, Urbany, Dickson and Wilkie ${ }^{21}$ divide uncertainty into two categories. Knowledge uncertainty includes uncertainty regarding information about alternatives, and choice uncertainty means uncertainty about which alternative to choose. Urbany et al. noted that choice uncertainty appeared to increase the amount of searching, as the comprehension of the results would be no problem. Knowledge uncertainty on the other hand seemed to lower the amount of search. Insights from Urbany et al. disagree somewhat with Alba and Hutchinson. The conclusions derived from both of these studies is that a certain amount of knowledge about the desired product is necessary to increase active information searching, even though potentially improved knowledge may reduce it.

Of all the possible products and brands that might satisfy a customer's needs, only a handful will be brought to the consumer's attention. Kotler ${ }^{22}$ defines four sets of alternatives from which the final purchase decision will be made. The total set includes all the possible brands available to the customer. Derived from the total set, is an awareness set, which includes the brands the customer has come to know. Brands that meet the buyer's purchasing criteria are taken from the awareness set to form the consideration set. As more information about the products of the consideration set is gathered and evaluated, the final purchase decision will be made from the choice set.

Peter and Olson ${ }^{23}$ define a similar process, which divides all the brands in the product class into familiar and unknown brands. From unknown brands, those that are found accidentally and those found through intentional search make it to the choice set. From familiar brands, only those that are activated from memory (evoked set) make it to the choice set. Among the familiar brands, there may be some that once have been familiar to the customer, but are lost in memory. Of the evoked set, brands that are liked more and thought more typical to the product class tend to emerge into the choice set. ${ }^{24}$

Narayana and Markin ${ }^{25}$ have extended 
the awareness set to consist of three different subsets. They define the evoked set as a set of products of which the consumer has a positive opinion and from which they are likely to make their purchase. Inert set includes products for which the consumer has neither negative nor positive opinion. The consumer may be aware of such products but not have formed an opinion, possibly due to lack of knowledge. The final set is called the inept set, which includes the products for which the consumer has formed a negative opinion, and therefore these products will not to be purchased.

No matter how one conceptualises these sets, the online environment gives the consumers a variety of different tools for information search to form these sets. Many companies have utilised so-called recommendation agents, which are interactive tools that assist the consumers in their screening of alternatives based on the information they have provided. Häubl and Trifts ${ }^{26}$ have gathered evidence that these recommendation agents 'reduce the number of alternatives for which detailed product information is viewed', thus reducing the search time of the consumers. One of the most common online search methods is browsing. Rowley ${ }^{27}$ asserts that browsing can be either general or purposive. Purposive browsing occurs when the consumer has fairly specific requirements of the needed product, as opposed to general browsing which is used to keep up to date with the latest knowledge concerning the product range. Rowley defines three distinctive purposes where browsing is preferred to search engines: (1) the search objective cannot be clearly defined; (2) the cognitive burden (ie the knowledge the consumer needs to have in order to do the searching) makes browsing easier; (3) the consumer's system interface encourages browsing over other methods of searching.

\section{Evaluation of alternatives}

Consumers tend to set rules, or attribute cut-offs for the products in their choice set. These are the minimum acceptable levels that an alternative must possess in order to be considered as the final purchase. Huber and Klein ${ }^{28}$ have showed two characteristics to these cut-offs. The first one states that when the reliability of the attribute the customer is considering is high (the information comes from a reliable source, at least in the customer's eyes), the cut-offs on that attribute are more severe than when reliability is low. The second characteristic is that when there is a positive correlation between two attributes (for example, low rent in a high-quality apartment), the cut-offs on those attributes are more severe than they would be if the correlation was negative or of equal magnitude. With respect to price, these cut-offs may however vary between online and offline transactions. Bhatnagar and Ghose ${ }^{29}$ found that price was not one of the major factors for online shoppers when they evaluate different alternatives. This may be because consumers might think the web prices are broadly similar and so they do not need to pay much attention to the price tag.

As consumers reduce their alternatives to the choice set, they have first acquired information about the products and then compared and evaluated them. As no consumer has unlimited resources (time, in this case) at their disposal, a line must be drawn as to when to stop the evaluation process and make the actual purchase decision. Hauser, Urban and Weinberg $^{30}$ propose that consumers allocate their time in such a fashion that when the trouble of getting extra information about the product outweighs the value of the additional information itself, information search and evaluation stop. More precisely, consumers try to 
maximise the equation $\sum_{s} v_{s}\left(t_{s}\right)+v_{0}\left(t_{0}\right)$, where $v_{s}\left(t_{s}\right)$ is the value of time $t_{s}$ spent gaining information about the product, and $v_{0}\left(t_{0}\right)$ is the value of time $t_{0}$ spent in other activities. As online evaluations can be done from a personal computer, saving the trouble of travelling from place to place, the equation changes so that we have an increase in $t_{0}$ and a decrease in $t_{s}$.

Still, consumers do not make their decisions based solely on the information about different brands, but also include how easy it is to process the information about the brand. A brand that is easily recognised by its physical characteristics is perpetually fluent, while a brand that comes to mind easily is conceptually fluent. Lee and Labroo $^{31}$ demonstrated that in their experiments that a brand becomes more conceptually fluent if the consumer has been exposed to related products just before they come into contact with the target product.

Following their example, a billboard advertising ketchup produced more conceptual fluency, when it was preceded with an advertisement for french fries compared with a washing detergent, thus the message from the billboard was easier to handle. In addition, with high conceptual fluency conditions, the brand evaluations tend to be more favourable. It is important to note, however, that if conceptual fluency creates negative associations, its effect will be negative. For example, the aforementioned advertisement of french fries may yield negative associations to the people that dislike them, which leads to less favourable evaluations of the ketchup ad. $^{32}$

This produces a great challenge for marketers in an online environment, as customers may be faced with a plethora of different advertisements, prior to the one that is needed to get their attention. This is where the new customisation technology has its advantages. By keeping record of individual customers' purchases and personal information, companies can now target their advertising accurately to each individual customer, ${ }^{33}$ thus having a chance to exploit the concept of conceptual fluency discussed above.

\section{Purchase decision}

After the evaluation stage, the consumer has ranked the items in the choice set in some sort of order but not always will the number one (if there is a number one assigned) item be chosen. There are two factors that come between the evaluation and purchase decision stages. ${ }^{34}$ First there are the attitudes of others, where best friends or community pressure may change a consumer's preference ranking for a certain brand even if they intended to buy a different one. Secondly there might be some unexpected situational factors that affect the purchase decision. The price of the product may have suddenly gone up, or some other purchase becomes more urgent. As online shopping usually occurs in a more private environment, other people's influences are reduced at the point of purchase. Even when a consumer has decided the exact product they are going to buy, there are still a few purchase sub-decisions to be made. ${ }^{35}$ These sub-decisions include price range, point of sale, time of purchase, volume of purchase, and method of payment.

In spite of all the theories on need recognition, information search, and evaluation as a fundamental basis for the purchase decision itself, there are situations where none of these processes apply. This phenomenon is called impulse purchasing. Impulse buying occurs when the consumer purchases an item based solely on their impulses and emotions. Baumeister ${ }^{36}$ submits that there 
are some genuinely irresistible impulses, mainly physiological, from which there is no escape, although they do not necessarily lead to purchase. This author continues to define three characteristics, which form consumer's self-control. To fail one of them might result in impulsive shopping given the right circumstances.

The first of these characteristics are the standards the individual has set for themselves. If consumers have set certain goals and norms and they know exactly what they want, they are less likely to act on impulse. This also reduces the vulnerability to sales personnel and advertisers. The second characteristic is monitoring. People who keep better track on their relevant behaviour are less prone to lose their self-control. Third and most important, is the consumer's capacity to change. Even if the two previous ingredients fail, there must be something inside the consumer that is willing to make the change and purchase the certain item their impulses suggest. ${ }^{37}$ Similar results were found by Sojka and Giese. $^{38}$

\section{Postpurchase behaviour}

The purchase process continues even after the actual purchase is made. If marketers and retailers want the customers to come back, they must understand their behaviour after the purchase as well. Postpurchase behaviour can be divided into two subgroups: postpurchase satisfaction and postpurchase actions. ${ }^{39}$ When it comes to postpurchase satisfaction, there is evidence offered by Mittal and Kamakura ${ }^{40}$ that consumers with different characteristics have different thresholds when it comes to loyalty towards the store even if they were dissatisfied with their purchase.

Oliver $^{41}$ has further discussed the concepts of loyalty (postpurchase action) and (postpurchase) satisfaction. Typically, loyal customers tend also to be satisfied but, according to Oliver, satisfaction does not necessarily produce loyalty. However, studies on several areas of consumer research such as Auh and Johnson, ${ }^{42}$ and Ball, Coelho and Machás ${ }^{43}$ emphasise how satisfaction indeed does produce loyalty.

The importance of satisfaction is as relevant in an online environment as it is in an offline world. Evanschitzky et al. ${ }^{44}$ have replicated a study by Szymanski and Hise $^{45}$ and have concluded that the single most important factor forming satisfaction in electronic commerce is the shopping convenience, which is a typical advantage of online shopping compared with conventional shopping. Typically, if a customer is not satisfied with the purchase, there is a chance that they will complain about the product/service. As the channels involving traditional and electronic commerce differ, it is not surprising that there are noted differences in the complaining threshold and the degree of dissatisfaction of the purchase in an online vs an offline environment as reported by Cho et al. ${ }^{46}$

In addition to satisfaction and loyalty, important issues in postpurchase actions include brand preference and repurchase intentions and how they affect each other. Hellier et al. ${ }^{47}$ have proposed a model where all these aspects are discussed and a number of hypotheses are derived. The following conclusions were made: loyalty has a positive effect on brand preference; satisfaction has a positive effect on loyalty; and brand preference and the strength of brand preference have a positive effect on repurchase intentions. If the aforementioned assumption by Evanschitzky et al. concerning the basic importance of satisfaction and its subsequent effects hold, it may be assumed that the conclusions offered by 
Hellier et al. are also valid in an online environment.

\section{AREAS OF STUDY AND PROBLEM CONCEPTUALISATION}

\section{Gender}

The first hypotheses discuss the differences between online shopping patterns of men and women. The basis of this research area is the work reported by Palanisamy, ${ }^{48}$ and Rodgers and Harris. ${ }^{49}$ According to Palasinamy, gender influences the relationship between online advertisement interpretation and the attitude toward the advertisement which in turn reflects the attitude towards the company. Thus, if the interpretation of an online advertisement is the same for both genders, but the attitude towards the ad is more positive by one gender, this would impact the perception of the entire buying process. Rodgers and Harris support this theory with their results. They claim that women are emotionally less gratified and have less satisfaction from online shopping than men. Men would also be more trusting than women and think that online shopping is more convenient.

Dholakia and Chiang ${ }^{50}$ suggest that men are often considered to be more technologically literate than women, a fact that is reflected especially in stereotypes that portray the online shopping event. There has been evidence found by Garbarino and Strahilevitz ${ }^{51}$ to support these stereotypes. Even though women have been closing the gender gap considering internet usage, it is still thought that women perceive higher risks than men in online purchasing in both probabilities and consequences. ${ }^{52}$

All the evidence above seems to indicate that there is indeed a difference in the way men and women perceive the entire online buying process. From this conclusion, the following general hypothesis is derived:

$\mathrm{H}_{1}$ : Gender influences the online buying process.

The first hypothesis is adjusted to fit the five-stage model. It is proposed that if the whole online buying process is considered to consist of five stages, it would be reasonable to test the assumption that gender influences all of the stages and not just some of them. Hence, the following hypotheses:

$\mathrm{H}_{1 \mathrm{a}}$ : Gender influences the need recognition phase of the online buying process.

$\mathrm{H}_{1 \mathrm{~b}}$ : Gender influences the information search phase of the online buying process.

$\mathrm{H}_{1 \mathrm{c}}$ : Gender influences the evaluation phase of the online buying process.

$\mathrm{H}_{1 \mathrm{~d}}$ : Gender influences the purchase decision phase of the online buying process.

$\mathrm{H}_{1 \mathrm{e}}$ : Gender influences the postpurchase phase of the online buying process.

\section{Differences in consumer online buying behaviour between 2002 and 2004/2005}

Once the connection between gender and the purchase process stages is established, an understanding of how the sampling period affects these stages is undertaken. There is also evidence that electronic commerce is growing rapidly in Finland ${ }^{53}$ and in the USA ${ }^{54}$ It would therefore be reasonable to assume that as electronic commerce is growing, online buying behaviour might also be changing. This leads to the next general hypothesis:

$\mathrm{H}_{2}$ : The time of sampling affects the online buying process. 
To examine this general hypothesis more thoroughly, it is separated into five smaller sub-hypotheses:

$\mathrm{H}_{2 \mathrm{a}}$ : The time of sampling affects the amount of need recognition.

$\mathrm{H}_{2 \mathrm{~b}}$ : The time of sampling affects the amount of information search.

$\mathrm{H}_{2 \mathrm{c}}$ : The time of sampling affects the amount of evaluation.

$\mathrm{H}_{2 \mathrm{~d}}$ : The time of sampling affects the amount of purchase decisions.

In this study, postpurchase behaviour is measured in terms of loyalty (the likelihood of repurchase). As Oliver ${ }^{55}$ has stated, loyal customers tend also to be satisfied, so the term postpurchase satisfaction is used here.

\section{$\mathrm{H}_{2 \mathrm{e}}$ : The time of sampling affects the amount of postpurchase satisfaction.}

\section{The effects of consumer online behaviour patterns on purchase volume}

The next point of interest is the relationship between purchase volume and different aspects of consumer behaviour. The following is proposed: the stronger (more positive) the consumer's affiliation to any given phase of the purchase process in an online environment, the higher the purchase volume will be. Evidence by Shang, Chen and Shen ${ }^{56}$ suggests that online shopping is not so much a goal-oriented activity rather than a result from cognitive absorption experiences from the web. So, according to theory by Shang et al., if a consumer discovers a product on the internet and uses it to obtain information about the said product, the cognitive absorption obtained during the process from the web may well result in online shopping. Therefore the following general hypothesis is proposed:

$\mathrm{H}_{3}$ : There is a positive relationship between the consumer's affiliation to the different stages of the buying process and the online purchase volume.

Next, it is assumed that the cognitive absorption proposed by Shang et al. influences all of the components in the buying behaviour process. Therefore, the general $\mathrm{H}_{3}$ hypothesis is broken down into five parts for each individual purchase process stage, where it is stated that those who use the internet more for need recognition etc. also purchase more online:

$\mathrm{H}_{3 \mathrm{a}}$ : There is a positive relationship between the amount of consumer online need recognition and the online purchase volume.

$\mathrm{H}_{3 \mathrm{~b}}$ : There is a positive relationship between the amount of consumer online information search and the online purchase volume.

$\mathrm{H}_{3 \mathrm{c}}$ : There is a positive relationship between the amount of consumer online evaluation and the online purchase volume.

$\mathrm{H}_{3 \mathrm{~d}}$ : There is a positive relationship between the amount of consumer online purchase decisions and the online purchase volume.

$\mathrm{H}_{3 \mathrm{e}}$ : There is a positive relationship between the amount of consumer online postpurchase satisfaction and the online purchase volume.

If a customer is satisfied with earlier purchases, it should produce store loyalty, which means more repurchases. ${ }^{57,58}$ If a customer has made several purchases from a particular website, they may have developed a routine pattern for purchasing online, or at least the 
threshold of purchasing online should be lower from that particular site. It is therefore concluded that customers who are likely to make a repurchase may have larger online purchase volume than those who have lower likelihood for repurchases, which leads to a following hypothesis:

$\mathrm{H}_{3 \mathrm{e}}$ : There is a positive relationship between the amount of consumer online postpurchase satisfaction and the online purchase volume.

\section{The effects of consumer online behaviour patterns to purchase volume change}

The former hypothesis combines certain parts of the $\mathrm{H}_{2}$ and $\mathrm{H}_{3}$ hypotheses. The $\mathrm{H}_{2}$ and $\mathrm{H}_{3}$ hypotheses questioned how the different behavioural characteristics affected the possible change in purchase volume between the sampling periods. That is to say that the possible increase in purchase volume might be greater among those with higher amount of online need recognition, etc. So if $\mathrm{H}_{2}$ and $\mathrm{H}_{3}$ are supported by the evidence, the following hypotheses may be proposed:

$\mathrm{H}_{4}$ : There is a positive relationship between the consumer's affiliation to the different stages in buying process and the possible changes in online purchase volume.

As with the preceding hypotheses, this general hypothesis may be separated into five sub-hypotheses:

$\mathrm{H}_{4 \mathrm{a}}$ : There is a positive relationship between the amount of consumer online need recognition and the possible changes in online purchase volume.

$\mathrm{H}_{4 \mathrm{~b}}$ : There is a positive relationship between the amount of consumer online information search and the possible changes in purchase volume.

$\mathrm{H}_{4 \mathrm{c}}$ : There is a positive relationship between the amount of consumer online evaluation and the possible changes in purchase volume.

$\mathrm{H}_{4 \mathrm{~d}}$ : There is a positive relationship between the amount of consumer online purchase decisions and the possible changes in purchase volume.

$\mathrm{H}_{4 \mathrm{e}}$ : There is a positive relationship between the amount of consumer online postpurchase satisfaction and the possible changes in purchase volume.

\section{METHODOLOGY}

The sampling plan required that a multi-page questionnaire be self-administered to randomly selected samples of students. The four separate and independent samples used in this study were gathered in Finland and the USA during 2002 and again in 2004/2005. The questionnaires used in the USA and Finland were identical except the Finnish students responded to the questionnaire in Finnish. The content of each question was carefully translated in order to match the English version. In addition, the Finnish students responded to the expenditure questions in terms of their local currency (Finnish markka). The Finnish currency responses were converted to US dollars using the exchange rate for the Finnish markka at the time of the data gathering.

The first two samples consisted of data gathered in Finland and the USA during 2002. The first sample consisted of 152 students attending a college located in northeast USA. The second sample of 194 was drawn from students attending a university located in Tampere, Finland. The third sample gathered data in 2004 
from 194 students attending two different universities in Tampere, Finland. The final sampling in 2005 consisted of 162 students at two institutions, one small private college and one large public university located in northeast USA.

In this study, the first of the five stages, need recognition, means either needs that are recognised directly online as external stimulus, or possible solutions (found online) to already existing needs. In the latter case the phase actually moves from need recognition to information search as the product shifts from the total set to awareness set, as defined by Kotler. ${ }^{59}$ In either case, this was regarded as need recognition and was measured by the question 'While online, I have discovered products and/or services that I am interested in.'

Information search means information acquired only from the internet through active searching. Therefore personal sources like instant messaging services or email do not apply, leaving commercial (advertising) or public (third-party websites) sources. The corresponding question is 'I have searched websites for information about products and/or services I am interested in.'

Evaluation has been measured as active evaluation. Active evaluation means that the evaluation process is happening through the internet with a possible intent to make a purchase at some point. Measurement of evaluation was carried out with the question 'I use websites to evaluate different services and/or products, brands, prices, features, and their availability.'

Perhaps the most crucial factor in the whole online buying process is the purchase decision itself. By definition, the online purchase decision means that the actual intent to purchase online has indeed occurred online. The question 'I make my final product and/or service purchase decisions while online' measures this.
Postpurchase actions have been studied through store loyalty. The respondents were asked whether they were likely to make a repurchase from an internet site, assuming they were happy with their earlier purchase.

All of these questions were measured on a three-point scale. The main challenge of this study was to determine the differences between the portions of the samples in relation to the explanatory variable (usually one of the buying process stages). When dealing with categorical variables, such as the 1-2-3 scale, chi-square testing was used. Along with the chi-square statistic and a corresponding $p$-value, the contingency coefficient was also computed to find out the strengths of the possible relationships.

When confronted with scale variables, such as purchase volume, the differences were sorted with the analysis of variance (ANOVA). If the homogeneity of variances held true, the regular $F$-statistic to calculate the $p$-value was used, but if this assumption did not hold, the $p$-value was calculated by using the Welch/Brown-Forsythe statistics. ${ }^{60,61}$ As ANOVA provides only results for sample mean values to be equal or not, regression analysis with dummy variables was used to find out which of the sample means differed from each other, along with their direction, magnitude and 95 per cent confidence limits. For more information on the statistical analyses carried out in this study, see eg Greenwood and Nikulin, ${ }^{62}$ Christensen, ${ }^{63}$ and Draper and Smith. ${ }^{64}$

\section{RESULTS}

\section{$H_{1}$ : Gender influences the online buying process}

The first hypothesis considered that gender affected the purchase process and, in particular, it was postulated that 
Table 1: Hypotheses H1: Gender

\begin{tabular}{lcll}
\hline Variable & Chi-square value & p-value & Contingency coefficient \\
\hline Finland & & & \\
Need recognition & 13.152 & 0.001 & 0.254 \\
Information search & 7.534 & 0.023 & 0.194 \\
Evaluation & 28.653 & 0.000 & 0.360 \\
Purchase decision & 17.179 & 0.000 & 0.287 \\
Postpurchase behaviour & 4.856 & 0.088 & - \\
USA & 1.844 & 0.398 & - \\
Need recognition & 1.229 & 0.268 & - \\
Information search & 1.248 & 0.536 & - \\
Evaluation & 0.674 & 0.714 & - \\
Purchase decision & 1.227 & 0.541 & - \\
Postpurchase behaviour & & & \\
\hline
\end{tabular}

gender influenced all of the five stages of purchase behaviour when these stages were observed separately. Table 1 displays the chi-square and $p$-values along with contingency coefficients where necessary for all of the five stages of purchase process. For most up-to-date results, only the 2004/2005 samples were used.

Table 1 clearly show how the online shopping process differs in terms of gender in Finland and the USA. The table shows that with a risk level of $\alpha=0.05$, the only variable that does not reject the null hypothesis of independence between genders in Finland is the postpurchase behaviour. The need recognition phase is the most problematic, as one of the expected frequencies was less than unity. However, the difference is so small that the results would be significant even if the observations were arranged so that the expected frequencies were greater than one. (If one female respondent had changed her mind and answered 'never' instead of 'sometimes' to the corresponding question, the $p$-value would have been 0.003). Therefore, the conclusion is that the difference is significant even with an expected value less than one.

Need recognition, evaluation, and purchase decision have fairly similar contingency coefficients meaning that the relations between gender and the different purchase process stages are about equally strong. Although the relation between gender and information search was statistically significant, it is clearly on the weaker side (compared with need recognition, evaluation, and purchase decision). In all of these cases, men were found to be more active than women.

The US sample showed that none of the purchase process stages differed when men and women were compared, providing strong evidence against the hypotheses. In the USA, the 2002 sample yielded similar results, showing that the online purchase process has remained approximately the same with both men and women over the last few years. In Finland, however, the earlier sample showed that the purchase process was much more similar between men and women two years ago than it is now. Should this trend continue in Finland, men would continue to be more active in the purchase process in the following years, a fact that companies and marketers need to acknowledge in order to get their messages to the desired audience. Given the trend in the USA, this is something that should not be of concern when targeting the US-based audience.

In summary, the Finnish results give 
Table 2: Summary of results for $\mathrm{H}_{1}$ hypotheses

\begin{tabular}{ll}
\hline $\mathrm{H}_{1 \mathrm{a}}$ : Gender influences the need recognition phase of online buying process. & $\mathrm{A}(\mathrm{FIN}) / \mathrm{R}(\mathrm{US})$ \\
$\mathrm{H}_{1 \mathrm{~b}}$ : Gender influences the information search phase of online buying process. & $\mathrm{A}(\mathrm{FIN}) / \mathrm{R}(\mathrm{US})$ \\
$\mathrm{H}_{1 \mathrm{c}}$ : Gender influences the evaluation phase of online buying process. & $\mathrm{A}(\mathrm{FIN}) / \mathrm{R}(\mathrm{US})$ \\
$\mathrm{H}_{1 \mathrm{~d}}$ : Gender influences the purchase decision phase of online buying process. & $\mathrm{A}(\mathrm{FIN}) / \mathrm{R}(\mathrm{US})$ \\
$\mathrm{H}_{1 \mathrm{e}}$ : Gender influences the postpurchase phase of online buying process. & $\mathrm{R}(\mathrm{FIN}) / \mathrm{R}(\mathrm{US})$ \\
\hline
\end{tabular}

$A=$ accepted,$R=$ rejected

Table 3: Hypotheses $\mathrm{H}_{2}$ : Time of sampling

\begin{tabular}{lcll}
\hline Variable & Chi-square value & p-value & Contingency coefficient \\
\hline Finland & & & \\
Need recognition & 12.649 & 0.002 & 0.178 \\
Information search & 12.249 & 0.002 & 0.175 \\
Evaluation & 30.022 & 0.000 & 0.268 \\
Purchase decision & 36.868 & 0.000 & 0.296 \\
Postpurchase behaviour & 8.644 & 0.013 & 0.187 \\
USA & & & \\
Need recognition & 4.557 & 0.102 & - \\
Information search & 14.564 & 0.001 & 0.212 \\
Evaluation & 19.027 & 0.000 & 0.240 \\
Purchase decision & 38.199 & 0.000 & 0.334 \\
Postpurchase behaviour & 10.569 & 0.005 & 0.199 \\
\hline
\end{tabular}

support to four of the first five

hypotheses, while the US sample did not support any of them. Table 2 gives an overview of these results.

\section{$\mathrm{H}_{2}$ : Differences in consumer online buying behaviour between 2002 and 2004/2005}

The second hypothesis suggested that there have been changes in the way consumers approach the general purchase process. As expected, the amount of online shopping has increased in both Finland and in the USA. It was also noticed that the average monetary amount of purchase has decreased in Finland, while the purchase quantities have increased, giving clues about more 'everyday' type of shopping. This gives reason to assume that should there be any changes in consumer behaviour, they are likely to be positive (more need recognition, information search etc). A chi-square test was first performed on all of the purchase process stages and if a statistically significant change was found in a positive direction, it was concluded that there was a positive relation to the purchase volume, thus accepting the hypotheses $\mathrm{H}_{2 \mathrm{a}}-\mathrm{H}_{2 \mathrm{e}}$. It is to be noted that even though a positive relationship between the possible increases in the buying process stages and purchase volumes were confirmed, no conclusions concerning the causal directions of these relationships may be established. It is equally likely that a large amount of online evaluation triggers the purchase decision because avid online buyers tend to evaluate the products online before purchase. Table 3 summarises the results of the chi-square analysis for different stages.

With a 5 per cent risk level, the only variables that supported the hypothesis of independence (contrary to the hypotheses) was need recognition in the USA. More importantly, ANOVA showed that all the increases measured were significant. Therefore, it can safely be concluded that there is a positive relationships between the increases in the aforementioned purchase process stages 
Table 4: Summary of results for $\mathrm{H}_{2}$ hypotheses

$\mathrm{H}_{2 \mathrm{a}}$ : The time of sampling affects the amount of need recognition.

$\mathrm{H}_{2 \mathrm{~b}}$ : The time of sampling affects the amount of information search.

$\mathrm{H}_{2 \mathrm{c}}$ : The time of sampling affects the amount of evaluation.

$\mathrm{H}_{2 \mathrm{~d}}$ : The time of sampling affects the amount of purchase decisions.

$\mathrm{H}_{2 \mathrm{e}}$ : The time of sampling affects the amount of postpurchase satisfaction.

$A=$ accepted,$R=$ rejected

and the increase in purchase quantity. When the samples were divided between men and women, it was found that all the stages that were significantly dependent were also significantly dependent when men and women were observed separately, so neither of the genders was 'responsible' for this positive relationship.

By definition, need recognition is triggered by either internal or external stimuli. Therefore, need recognition is passive in nature. Need recognition does not require any active measures from the end user. Marketers could benefit from identifying the circumstances and conditions where these stimuli are triggered, so that they could communicate the appropriate information to the customers as suggested by Kotler. ${ }^{65}$ In Finland, this information has been received rather successfully in the past couple of years, while in the USA there appears to be no visible change. Due to this finding, one may question whether the US online markets are already too saturated with information from advertisements. US customers have changed their attitudes and behaviour towards such promotional information by not paying as much attention to it as they did in the past. These customers feel that many forms of delivery of online promotional information such as banner and skyscraper ads, pop-up and pop-under ads are a nuisance, intrusive and annoying, and they should be blocked from their online browsing. For example, a 2001 study by nua Internet Surveys ${ }^{66}$ found that 62 per cent of web surfers indicated that pop-ups interfered with their use of webpages. Additionally, there may be something fundamentally different in the Finnish marketplace. Possibly the strategies used to trigger need recognition are more effective for the Finnish customers at this stage.

Thus, it has been established that the purchase process is dependent on gender and sampling time. It is no surprise that it has also been determined that the amount of online shopping has increased in both countries between the two samples. Hypotheses $\mathrm{H}_{3}$ and $\mathrm{H}_{4}$ explore more deeply into the relationships between purchase volume increase and purchase process behaviour. Table 4 summarises the results derived from $\mathrm{H}_{2}$.

\section{$\mathrm{H}_{3}$ : The effects of consumer online behaviour patterns to the purchase volume}

The third hypothesis suggested that there is a positive relationship between the affiliation to the different factors that influence the buying process and the purchase volume. This hypothesis was tested with ANOVA and regression analysis using dummy variables. Most of the respondents answered that their affiliation to any given factor was either high or moderate, and therefore the responses where the number was equal to or less than 5 per cent of the total responses were omitted. The results from the Finnish 2004 sample supported this theory for all of the five stages. Table 5 shows the means of purchased items in the last 12 months for all the variables 
Table 5: Hypotheses $\mathrm{H}_{3}$ : Purchase volume

\begin{tabular}{lllllll}
\hline & $\begin{array}{l}\text { Amount } \\
\text { High } \\
\text { Mean }\end{array}$ & $\boldsymbol{p}$-value & $\begin{array}{l}\text { Moderate } \\
\text { Mean }\end{array}$ & $\boldsymbol{p}$-value & $\begin{array}{l}\text { Low } \\
\text { Mean }\end{array}$ & $\boldsymbol{p}$-value \\
\hline Finland & & & & & & \\
Need recognition & 6.54 & 0 & 1.80 & 0.000 & - & - \\
Information search & 4.99 & 0 & 2.03 & 0.003 & - & - \\
Evaluation & 4.98 & 0 & 2.52 & 0.017 & - & - \\
Purchase decision & 6.24 & 0 & 2.85 & 0.003 & 0.84 & 0.004 \\
Postpurchase behaviour & 8.02 & 0 & 2.83 & 0.000 & - & - \\
USA & 17.76 & 0 & 8.21 & 0.001 & - & - \\
Need recognition & 14.62 & 0 & 7.93 & 0.009 & - & - \\
Information search & 14.97 & 0 & 8.70 & 0.019 & - & - \\
Evaluation & 24.96 & 0 & 8.77 & 0.000 & 2.20 & 0.000 \\
Purchase decision & 14.74 & 0 & 8.08 & 0.020 & - & - \\
Postpurchase behaviour & & & & & & - \\
\hline
\end{tabular}

followed by $p$-values from regression analysis classified by the affiliation (high, moderate and low) for each variable. The $p$-values indicate the difference from 'high' internet usage with null hypothesis being that this difference is 0 . Given the 5 per cent risk level, there is a clear indication of a positive relationship with need recognition, information search, evaluation, purchase decision and postpurchase satisfaction in Finland.

Table 5 shows how the purchase decision mean values drop in Finland as the level of internet usage in different stages decreases with the first five variables. When men and women were observed separately, few interesting findings were made. From the Finnish sample, the results showed how online evaluation is positively related to purchase volume. However neither men's nor women's separate samples supported these findings. The most likely reason is that as the $\mathrm{p}$-value was quite high (0.042) to begin with, the decreases in usable observations reduced the $F$-values enough to raise the $p$-value above 5 per cent. The data also suggest that there are no dependencies between the purchase volume and the levels of information search or purchase decision as far as women are concerned. In the USA, the results from the male sample supported the hypotheses, with the exception of postpurchase behaviour on all occasions. The results from the female sample only support the cases of need recognition, purchase decision, and postpurchase behaviour. Table 6 summarises the results from $\mathrm{H}_{3 \mathrm{a}}-\mathrm{H}_{3 \mathrm{e}}$.

\section{$\mathrm{H}_{4}$ : The effects of consumer online behaviour patterns to purchase volume change}

It has been established that in both countries there is an increase in the purchase volume between the earlier and the later samples, and that there is a positive relationship between some of the purchase process stages and purchase volume. The fourth hypothesis suggests that there is a positive relationship between the purchase process stages and the increase in purchase volume. While the mean results support this hypothesis fairly well, in reality things are not as simple as they seem. In most of the Finnish samples' cases, the majority of the respondents belong to the middle group, leaving rather few observations for the extreme ends of the spectrum. This leads to large standard deviations and to the fact that the test statistics for ANOVA and regression analysis would need to be much larger for the extreme 
Table 6: Summary of results for $\mathrm{H}_{3}$ hypotheses

$\mathrm{H}_{3 \mathrm{a}}$ : There is a positive relationship between the amount of consumer online need recognition and the online purchase volume.

$\mathrm{H}_{3 \mathrm{~b}}$ : There is a positive relationship between the amount of consumer online information search and the online purchase volume.

$\mathrm{H}_{3 \mathrm{c}}$ : There is a positive relationship between the amount of consumer online evaluation and the online purchase volume.

$\mathrm{H}_{3 \mathrm{~d}}$ : There is a positive relationship between the amount of consumer online purchase decisions and the online purchase volume.

$\mathrm{H}_{3 \mathrm{e}}$ : There is a positive relationship between the amount of consumer online postpurchase satisfaction and the online purchase volume.

$A=$ accepted,$R=$ rejected

groups than for the middle group to make any statistical significance. In the USA, most of the respondents fell into the 'high' and 'moderate' groups reducing the usefulness of the statistical analyses as far as the 'low' group is concerned.

In Finland, the statistical differences that suggest any support for the general $\mathrm{H}_{4}$ hypothesis, were significant only with $\mathrm{H}_{4 \mathrm{a}}$ and $\mathrm{H}_{4 \mathrm{~b}}$. The increases in purchase volume were significantly larger $(\alpha=0.05)$ for people with a high frequency in online need recognition and information search. In the USA, supportive evidence was found for $\mathrm{H}_{4 a}$, $\mathrm{H}_{4 \mathrm{~b}}$, and $\mathrm{H}_{4 \mathrm{~d}}$. As was the case with Finland, the increases in purchase volume in the USA was larger for people with a high frequency in online need recognition and information search, and no differences were found in the 'low' groups. With postpurchase satisfaction, the differences were less between the high and moderate groups, but as in the low group, there was no increase at all, there is enough support for $\mathrm{H}_{4 \mathrm{~d}}$ in the USA. Overall the USA increases were significantly larger than Finnish. Table 7 lists the $p$-values from ANOVA and regression analysis. If the assumption of homogenous variances failed, ${ }^{67,68}$ the statistics were computed instead of the usual F-statistic. Table 7 also lists the $\beta$-coefficients (when statistically different from zero) obtained from regression analysis. These coefficients show the differences between the mean values of the 2002 and 2004/2005 samples.

The conclusion for this hypothesis is unclear. The mean results give support in some form to all of hypotheses $\mathrm{H}_{4 \mathrm{a}}-\mathrm{H}_{4 \mathrm{e}}$, but statistical evidence only supports hypotheses $\mathrm{H}_{4 \mathrm{a}}$ and $\mathrm{H}_{4 \mathrm{~b}}$ in Finland, and $\mathrm{H}_{4 \mathrm{a}}, \mathrm{H}_{4 \mathrm{~b}}$ and $\mathrm{H}_{4 \mathrm{~d}}$ in the USA. As there is always the possibility that the mean values were due to chance (that is, indeed, what the results from ANOVA indicate), all hypotheses that did not have statistical support from the analyses are rejected. However, it must be recognised that there might be some truth in the hypotheses that were rejected. Given more observations, the test statistics might show significant differences similar to the hypotheses. Table 8 sums up the hypotheses of $\mathrm{H}_{4}$ as they were computed above.

\section{CONCLUSIONS AND LIMITATIONS}

From the results it seems clear that online shopping has increased in popularity among both male and female portions of the target groups in Finland, and more so in the USA. The internet also has increased in popularity as a tool used to contribute to and assist in the buying process. In spite of the increase in both genders, it seems that in Finland, men tend to recognise more needs online and use the internet for information search and evaluation more 
Table 7: Hypotheses $\mathrm{H}_{4}$ : Change in purchase volume

\begin{tabular}{|c|c|c|c|}
\hline & & $p$-value & $\beta$ \\
\hline \multicolumn{4}{|l|}{ Finland } \\
\hline \multirow[t]{3}{*}{ Amount of online need recognition } & High & 0.033 & 3.522 \\
\hline & Moderate & 0.000 & 1.072 \\
\hline & Low & $-^{\mathrm{a}}$ & - \\
\hline \multirow[t]{3}{*}{ Amount of online information search } & High & 0.019 & 2.68 \\
\hline & Moderate & 0.000 & 1.312 \\
\hline & Low & $-{ }^{a}$ & - \\
\hline \multirow{3}{*}{ Amount of online evaluation } & High & 0.069 & - \\
\hline & Moderate & 0.002 & 1.496 \\
\hline & Low & 0.810 & - \\
\hline \multirow{3}{*}{ Amount of online purchase decision } & High & 0.176 & - \\
\hline & Moderate & 0.023 & 1.300 \\
\hline & Low & 0.008 & 0.685 \\
\hline Amount of postpurchase behaviour & High & 0.070 & - \\
\hline \multirow[t]{2}{*}{ (likelihood of repurchase) } & Moderate & 0.635 & - \\
\hline & Low & 0.585 & - \\
\hline \multicolumn{4}{|l|}{ USA } \\
\hline \multirow[t]{3}{*}{ Amount of online need recognition } & High & 0.005 & 12.018 \\
\hline & Moderate & 0.000 & 4.945 \\
\hline & Low & 0.743 & - \\
\hline \multirow[t]{3}{*}{ Amount of online information search } & High & 0.002 & 9.049 \\
\hline & Moderate & 0.000 & 4.656 \\
\hline & Low & $-^{a}$ & - \\
\hline \multirow{3}{*}{ Amount of online evaluation } & High & 0.024 & 8.286 \\
\hline & Moderate & 0.000 & 5.336 \\
\hline & Low & 0.015 & 8.449 \\
\hline \multirow[t]{3}{*}{ Amount of online purchase decision } & High & 0.082 & - \\
\hline & Moderate & 0.006 & 3.526 \\
\hline & Low & 0.062 & - \\
\hline \multirow{3}{*}{$\begin{array}{l}\text { Amount of postpurchase behaviour } \\
\text { (likelihood of repurchase) }\end{array}$} & High & 0.015 & 8.825 \\
\hline & Moderate & 0.007 & 4.538 \\
\hline & Low & $-a^{a}$ & - \\
\hline
\end{tabular}

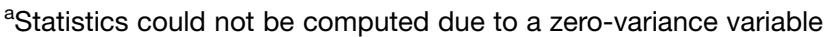

Table 8: Summary of results for $\mathrm{H}_{4}$ hypotheses

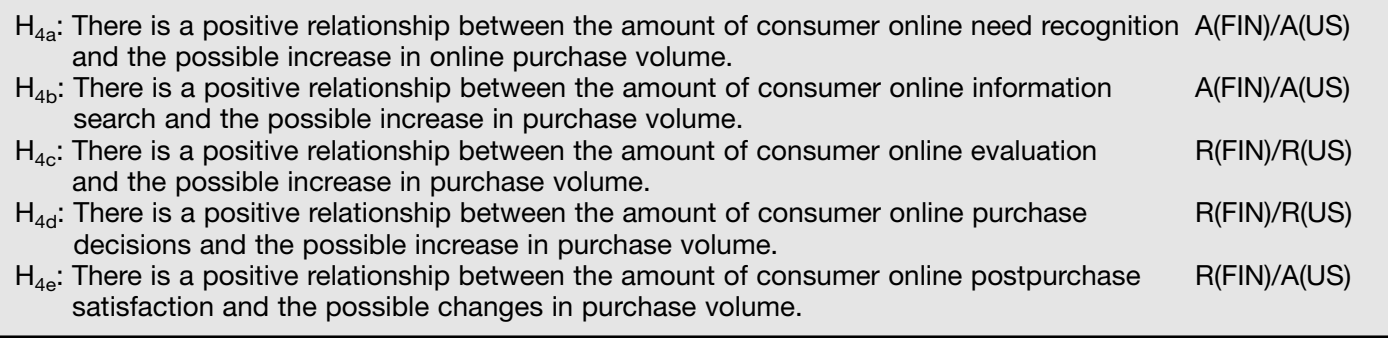

$A=$ accepted,$R=$ rejected

than women. Finnish men also showed a higher frequency in online purchase decisions and postpurchase behaviour. In the USA, there was no such gender gap, showing that the online shopping orientation between men and women did not differ significantly.

The distribution for most frequent shoppers is bound to be changing over time, as new services and products emerge in the markets, along with better logistic solutions for delivery and handling. The two-year span of this study, however, was not enough to capture any large changes. Affordable airline tickets made available online are 
still a good example of a product that has gained popularity, and although not listed in the questionnaire, online ordering of train tickets was mentioned by many respondents in Finland. Online train ticket services are still a fairly new phenomenon in Finland, and if the increase in airline tickets is an indication, the demand for online train tickets may increase in the future, especially among the Net Generation in Finland (for example, students get a 50 per cent discount from train tickets, plus many of them live away from their hometown). The effects on the general population remain to be seen.

When the buying process is defined by the five-stage purchase model, it is evident that the internet is playing a continuously increasing role. When the amount of internet usage related to different phases of the model was measured, a statistical increase in both countries from 2002 to 2004/2005 was found with the largest increases being in the purchase decision itself. There is no reason to assume that this trend will decrease anytime soon. The Net Generation in both Finland and the USA have been enjoying affordable broadband connections for some time now, and these consumers are familiar with the advantages the internet has to offer. This trend is also likely to spread to the rest of the population, as the number of internet service providers offering inexpensive broadband connections increases. This will certainly push the internet penetration rate even higher. No changes in need recognition were measured, but a slight increase in the trust factor was noted. In light of current internet connectivity technology (ICT) developments, this trend is likely to continue in both countries.

This study shows clearly that the Net Generation segment of the population with high internet usage relative to the different stages of the purchase process, tends to buy more from the internet. This phenomenon is occurring generally with men and women in both of the target countries. The need recognition phase in particular is of interest because the results show that if a potential customer frequently discovers products they need while online, they are likely to make more purchases than those who use the internet frequently for only information search or evaluation. In Finland, the results suggest that the frequency of need recognition has a greater influence on the number of goods bought from the internet than the frequency of online purchase decisions themselves. The results also clearly show that it is worthwhile for e-marketers to keep their customers satisfied. If the e-marketer satisfies the customer, that customer is a prime candidate for a repurchase. As the total number of online purchases continues to increase, the e-marketer who effectively serves, satisfies, and delights their online buyers will enjoy repeat patronage.

This study has shown that the widely discussed five-stage model for consumer buying behaviour has implications in the online environment. Although online shopping in general does not depend on the geographical location (neither buyer's nor vendor's), the cultural differences, along with the ICT infrastructure, do affect the process as was illustrated in this study. Even though Finland and the USA both have a very high level of sophistication in the ICT field, the US online shopping field could be described as somewhat more convergent, because men and women are frequently marketed to as separate segments. The increase in US online shopping also was significantly larger than in Finland. As there is clear growth in online purchase volume in both countries and in fact globally, e-marketers may be guided by the 
findings of hypothesis $\mathrm{H}_{4}$. E-marketers should continue to design and deliver effective online support for the need recognition, information search, and purchase decision stages of the consumer buying decision process. Additionally, the online evaluation and postpurchase satisfaction stages should be prioritised for continued investigation, better understanding, and improvement. Particularly in emerging online markets, during the introduction and growth phases of online purchasing, gender may influence all but the postpurchase stage of the consumer buying decision process, with males being more active than females. These results provide important guidance as to how the five-stage purchase process model could be utilised by e-vendors to improve their marketing online.

It is essential to acknowledge the limitations of this study that reduce the generalisability of the findings. The main limitations of this study are the samples. University students, as part of the Net Generation, are extensive users of the latest information technology. This makes them ideal for this study because they all utilise computers frequently. The bias may come from the fact that these samples represent only a portion of the population that have above average computer skills, as well as free access to the internet. Thus, any generalisations to the general population should be made with caution. Internet usage is, however, increasing in all segments of the population. Given that this study was not intended to establish the proportion of the population that use the internet to purchase online, but was intended to investigate the buyer decision process of those that do, the Net Generation's highly literate and heavy online users are certainly more qualified and better able to provide the requisite information.

Additionally, a third reference point would have been beneficial in obtaining more accurate information about the behavioural trends in online shopping, instead of just drawing conclusions from previous trends of development.

According to this and previous reports, however, there is no need to assume that the amount of online shopping will diminish anytime soon.

\section{References}

1 Alch, M. (2000) 'Get ready for a new type of worker in the workplace: The Net Generation', Supervision, Vol. 61, No. 4, pp. 3-7.

2 World Economic Forum (2004) 'Networked Readiness Index'; available at: http://www.weforum.org/pdf/Global_ Competitiveness_Reports/Reports/GITR_2004_ 2005/Networked_Readiness_Index_Rankings.pdf, accessed 26th May, 2005.

3 Kotler, P. and Kelle, K. L. (2006) 'Marketing Management' (12th edn), Prentice Hall, Upper Saddle River, NJ, pp. 191-199.

4 Jobber, D. and Lancaster, G. (2003) 'Selling and Sales Management' (6th edn), Prentice Hall, Upper Saddle River, NJ, p. 216.

5 Roth, R. (2001) 'Yes, customer control is fundamental change', InternetWeek, February, p. 23.

6 Fader, P. (2001) 'No, it doesn't change basic buying patterns', InternetWeek, February, p. 23.

7 Kotler and Kelle (2006), see ref. 3 above.

8 Kotler, P. and Armstrong, G. (2005) 'Marketing: An Introduction', Prentice Hall, Upper Saddle River, NJ, p. 165.

9 Kinnear, T. and Bernhardt, K. (1986) 'Principles of Marketing' (2nd edn), Scott, Foresman and Co., Glenview, IL, p. 146.

10 Ibid, p. 149.

11 Ibid.

12 Ibid, p. 150.

13 Dubois, B. (2000) 'Understanding the Consumer', Prentice Hall, Upper Saddle River, NJ, p. 229.

14 Van Trijp, H., Hoyer, W. and Inman, J. (1996) 'Why switch? Product category-level explanations for true variety-seeking behavior', Journal of Marketing Research, Vol. 33, No. 3, pp. 281-292.

15 Kotler and Kelle (2006), see ref. 3 above, pp. 191-192.

16 Ibid.

17 Dubois (2000), see ref. 13 above, p. 231.

18 Alba, J. and Hutchinson, J. (1987) 'Dimensions of consumer expertise', Journal of Consumer Research, Vol. 13, No. 4, pp. 411-454.

19 Beatty, S. and Smith, S. (1987) 'External search effort: an investigation across several product categories', Journal of Consumer Research, Vol. 14, No. 1, pp. 83-95.

20 Biswas, D. (2004) 'Economics of information in the Web economy: Towards a new theory?', Journal of 
Business Research, Vol. 57, No. 7, pp. 724-733.

21 Urbany, J., Dickson, P. and Wilkie, W. (1989) 'Buyer uncertainty and information search', Journal of Consumer Research, Vol. 16, No. 2, pp. 208-215.

22 Kotler and Kelle (2006), see ref. 3 above, pp. 192-193.

23 Peter, J. and Olson, J. (1996) 'Consumer Behavior and Marketing Strategy' (4th edn), Irwin/McGraw-Hill, Boston, Massachusetts, p. 200.

24 Klenosky, D. and Rethans, A. (1988) 'The formation of consumer choice sets: a longitudinal investigation at the product class level', Advances in Consumer Research, Vol. 15, No. 1, pp. 13-18.

25 Narayana, C. and Markin, R. (1975) 'Consumer behavior and product performance: an alternative conceptualization', Journal of Marketing, Vol. 39, No. 4, pp. 1-6.

26 Häubl, G. and Trifts, V. (2000) 'Consumer decision making in online shopping environments: the effects of interactive decision aids', Marketing Science, Vol. 19, No. 1, pp. 4-21.

27 Rowley, J. (2000) 'Product search in e-shopping: a review and research propositions', Journal of Consumer Marketing, Vol. 17, No. 1, pp. 20-35.

28 Huber, J. and Klein, N. (1991) 'Adapting cutoffs to the choice environment: the effects of attribute correlation and reliability', Journal of Consumer Research, Vol. 18, No. 3, pp. 346-357.

29 Bhatnagar, A. and Ghose, S. (2004) 'A latent class segmentation analysis of e-shoppers', Journal of Business Research, Vol. 57, No. 7, pp. 758-767.

30 Hauser, J., Urban, G. and Weinberg, B. (1993) 'How consumers allocate their time when searching for information', Journal of Marketing Research, Vol. 30, No. 4, pp. 452-466.

31 Lee, A. and Labroo, A. (2004) 'The effect of conceptual and perceptual fluency on brand evaluation', Journal of Marketing Research, Vol. 41, No. 2, pp. 151-165.

32 Ibid.

33 Kotler and Armstrong (2005), see ref. 8 above, pp. 36-37.

34 Ibid, p. 169.

35 Dubois (2000), see ref. 13 above, p. 239.

36 Baumeister, R. (2002) 'Yielding to temptation: self-control failure, impulsive purchasing and consumer behavior', Journal of Consumer Research, Vol. 28, No. 4, pp. 670-676.

37 Ibid.

38 Sojka, J and Giese, J. (2003) 'Using individual differences to detect customer shopping behavior', The International Review of Retail, Distribution and Consumer Research, Vol. 13, No. 4, pp. 337-353.

39 Kotler and Kelle (2006), see ref. 8 above, pp. 198-199.

40 Mittal, V. and Kamakura, W. (2001) 'Satisfaction, repurchase intent and repurchase behavior: investigating the moderating effect of customer characteristics', Journal of Marketing Research, Vol. 38, No. 1, pp. 131-142.

41 Oliver, R. (1999) 'Whence consumer loyalty?', Journal of Marketing, Vol. 63, No. 4, pp. 33-44.
42 Auh, S. and Johnson, M. (2005) 'Compatibility effects in evaluations of satisfaction and loyalty', Journal of Economic Psychology, Vol. 26, No. 1, pp. 35-37.

43 Ball, D., Coelho, P. and Machás, A. (2004) 'The role of communication and trust in explaining customer loyalty', European Journal of Marketing, Vol. 38, No. 9/10, pp. 1272-1293.

44 Evanschitzky, H., Iyer, G., Hesse, J. and Ahlert, D. (2004) 'E-satisfaction: a re-examination'. Journal of Retailing, Vol. 80, No. 3, pp. 239-247.

45 Szymanski, D. M. and Hise, R. T. (2000) 'E-satisfaction: an initial examination', Journal of Retailing, Vol. 76, No. 3, pp. 309-322.

46 Cho, Y., Im, I., Hiltz, R. and Fjermestad, J. (2002) 'The effects of post-purchase evaluation factors on online vs offline customer complaining behavior: implications for customer loyalty', Advances in Consumer Research, 29, No. 1, pp. 318-326.

47 Hellier, P., Geurse, G., Carr, R. and Rickard, J. (2003) 'Customer repurchase intention: a general structural equation model', European Journal of Marketing, Vol. 37, No. 11/12, pp. 1762-1800.

48 Palanisamy, R. (2004) 'Impact of gender differences on online consumer characteristics on web-based banner advertising effectiveness', Journal of Services Research, Vol. 4, No. 2, pp. 45-74.

49 Rodgers, S. and Harris, M. (2003) 'Gender and e-commerce: an exploratory study', Journal of Advertising Research, Vol. 43, No. 3, pp. 322-329.

50 Dholakia, R. and Chiang, K. (2003) 'Shoppers in cyberspace: are they from Venus or Mars and does it matter?', Journal of Consumer Psychology, Vol. 13, No. $1 / 2$, pp. $171-176$.

51 Gabriano, E. and Strahilevitz, M. (2004) 'Gender differences in the perceived risk of buying online and the effects of receiving a site recommendation', Journal of Business Research, Vol. 57, No. 7, pp. $768-775$.

52 Ibid.

53 Sähköisen Kaupan Palvelukeskus (2004) 'Suomi: internet-kuluttajakaupan arvo 2,1 miljardia euroa', available at: http://www.e-finland.org/ cgi-bin/center/xhtml?/pageID $=53 / /$ list $=3 /$ from $=4 /$ size $=1 /$ sort $=$ down $+25 /$ find $=+/$ show, accessed 24th May, 2005.

54 The Census Bureau of the Department of Commerce (2005) US Census Bureau News, http://www.census.gov/mrts/www/data/pdf/ 05Q1.pdf, accessed 24th May, 2005.

55 Oliver (1999), see ref. 41 above.

56 Shang, R., Chen, Y. and Shen, L. (2005) 'Extrinsic versus intrinsic motivations for consumers to shop on-line', Information and Management, Vol. 42, No. 3, pp. 402-413.

57 Auh and Johnson (2005), see ref. 42 above.

58 Ball, Coelho and Machás (2004), see ref. 43 above.

59 Kotler and Kelle (2006), see ref. 3 above, pp. 192-193.

60 Welch, B. L. (1951) 'On the comparison of several means values: an alternative approach', Biometrika, 
Vol. 38, No. 3/4, pp. 330-336.

61 Brown, M. B. and Forsythe, A. B. (1974) 'The ANOVA and multiple comparisons for data with heterogeneous variances', Biometrics, Vol. 30, No. 4 , pp. 719-724.

62 Greenwood, P. and Nikulin, M. (1996) 'A Guide to Chi-Squared Testing', John Wiley and Sons, Inc., Hoboken, NJ, pp. 86-90.

63 Christensen, R. (1996) 'Analysis of Variance, Design and Regression', Chapman \& Hall, London, pp.
108-140.

64 Draper, N. and Smith H. (1981) 'Applied

Regression Analysis' (2nd edn), John Wiley and Sons, Inc., Hoboken, NJ, pp. 241-250.

65 Kotler and Armstrong (2005), see ref. 8 above, p. 204.

66 nua Internet Surveys, 3 May, 2001,

http://www.nua.ie, accessed 28th May, 2001.

67 Welch (1951), see ref. 60 above.

68 Brown and Forsythe (1974), see ref. 61 above. 